\title{
Research on E-commerce Logistics System Informationization in China
}

\author{
Xianglian Chen, Zhengxiang Yang \\ Department of Logistics, Wuhan Technical College of Communications, China \\ Department of Electronics and Information, Wuhan Technical College of Communications, China \\ cxl8312@126.com
}

Keywords:e-commerce; the logistics mode; logistics system informationization

\begin{abstract}
E-commerce is an important driving force of the world economic development. The emergence of modern logistics in e-commerce environment, made the logistics in the development of informationization, networking, intelligent direction, The logistics industry in China started late, not modern enough, restricting the development of e-commerce logistics in China. This article research base on the domestic and international study of e-commerce logistics, analyze the characteristics and mode of e-commerce logistics, combined with the current situation and existing problems of e-commerce logistics in china, which proposed the development trend of e-commerce logistics system information technology in china is the integration of Logistics and Purchasing.
\end{abstract}

\section{Introduction}

Accompanying the coming of network economy era, e-commerce has become the latest model of commodity trading. E-commerce is a fashion electronicpayment transactionin the wide network environment, with the use of computer and information technology, consumer online shopping, online transactions between enterprises and services. From the process of e-commerce activities, it is the unification of the business flow, information flow, capital flowand logistics. Now lots of companies are entering in e-commerce activities with various forms. The emergence of e-commerce, on the one hand, brought convenience to the lives of people; the other hand developed a new channel to the expansion of the business. The e-commerce business can be completed on the network, realizefinal trading but rely on logistics support. Without an efficient, reasonable, smooth logistics system, the advantage of e-commerce would be difficult to function effectively. Especially, the degree of backwardness and modernization of logistics industry in china is not enough, in e-commerce era now, supporting the modernization logistics support of e-commerce activities have not been well developed. So this paper through the study of information about the current situation of e-commerce logistics system in china and our existing logistics model, which proposed the development trend of e-commerce logistics system in china.

\section{Research Status at Home and Abroad}

In (Global Logistics Management) book, The Kent N.Gourdin proposed the e-commerce logistics service quality model, and the study found that logistics has a very important position in e-commerce. The Scholar Haul. Lee and Seungin Whang, from America, in the article of (Winning the last mile of E-Commence) pointed out that logistics can achieve the end of the online trading commodity distribution, and is the last link of completing the entire e-commerce activities. In the field of modes of e-commerce logistics system, the Georgia Institute of Technology, the University of Shenyang Naxi joint commenced research of the third-party logistics in e-commerce applications. The research results show that the third-party logistics has become the best mode of e-commerce logistics mode; it would bring great economic and social benefits to e-commerce and distribution of third-party logistics. Because the market economy in Western developed countries is maturing, and the management of logistics market is standardized, their research areas are mainly concentrated in the supply chain management, third party logistics and distribution patterns, rarely appear similar problems of e-commerce logistics in china, copying foreign research is not feasible. 
In recent years, logistics scholars in china study on e-commerce logistics system, mainly concentrate on the logistics system mode relationship with e-commerce. For example, Wang Zhitai thinks ,modern logistics and network economy together create e-commerce, e-commerce is a product of the network economy and logistics integration, Image with "e-commerce $=$ online information delivery + online trading + online billing + logistics distribution" to show that the relationship between the distribution and e-commerce, e-commerce can also be expressed as "mouse + wheel". Domestic theoretically demonstrate that logistics has become the bottleneck of the development of electronic commerce, the development of the logistics required the development of e-commerce. But the reality is not close enough. For different enterprises how to choose the right e-commerce logistics mode, on the real problem there doesn't give a good solution

\section{Characteristics of E-commerce Logistics Systems and Logistics Mode}

\subsection{Characteristics of e-commerce logistics system}

A High Degree of Informationization. The era of e-commerce, logistics informationization is the inevitable requirement of e-commerce. The logistics process informational includes the commercialization of logistics information, logistics information collection database, electronic logistics information processing, logistics information transfer and standardization. With the GPS information system and a variety of powerful database system, Enterprises can clearly understand the in transit goods (location, variety, quantity, etc.) and the current state.

Network. Logistics network is the inevitable trend of logistics informationization. In today's world, the popularity of the global network resources provided by the Internet and network technology to provide a favorable external environment for the logistics network. If you leave the network, the logistics information can only internal circulation, transfer and sharing of information has become impossible, and communication between the various links of the supply chain will also be difficult.

Intellectualization. Intellectualization is to establish a high-level logistics information network on top of the application. The operation of the logistics process has a great majority operation and decision-making, only with the help of a computer precision computing and smart arrangements that can be resolved. Only achieve logistics intellectualization that can improve the efficiency of logistics, improve the entire supply chain flexibility to arrange the supply and marketing based on customer demand reduce the "bullwhip effect", and realize low inventory and high efficiency.

3.2 e-commerce logistics mode. So far our main logistics development mode: the mode of self-logistics, third party logistics mode, logistics Alliance mode and logistics integration.

Self-logistics Model. elf-logistics mode is the e-commerce businesses to set up their own logistics distribution system, the entire logistics operation process of the operation and management of enterprises. Take self-logistics mode of e-commerce enterprises are mainly of two types: one is the financial strength and large-scale business e-commerce company. The second category is the traditional largely manufacturing companies or wholesale business e-commerce website.

The e-commerce company's self-logistics required generous inputs, and after the completion of a required high large scale, after the completion of staff with professional logistics management capabilities. The overall quality of personnel within the enterprise engaged in logistics management is not high, the theory of logistics and logistics education in china seriously lagging behind, resulting in our logistics personnel is a serious shortage, cannot solve a variety of complex and diverse e-commerce logistics problems.

Third-party Logistics Mode. The third-party logistics mode also is known as outsourcing logistics or contract logistics. The third-party logistics (3PL) supply-side and demand-side by the logistics labor parties outside of the third-party logistics works to complete logistics services.

It itself does not have the goods, but through cooperation agreements or partnering with a coalition, personalized logistics agent service to customers in accordance with a specific price in a specific period of time. Due to advanced technology, more complete distribution system, third-party logistics for its fast delivery speed, high efficiency become one of the ideal solution for e-commerce logistics distribution. In addition to the strength of the self-logistics system of large enterprises, more SMEs tend to use outsourcing. Practice has proved that efficient third-party logistics services meet 
both the client's complex logistics service requirements, at the same time reduce the burden of the e-commerce businesses, in order to advance the social division of labor.

Logistics Alliance. Logistics Alliance is a cross logistics mode, set up in the front between the two modes, can reduce the risk of the first two modes, and easier to operate for enterprises. Logistics Alliance is a long-term joint cooperation of two or more of the economy taken by the organization to achieve the specific logistics goal. The aim is to achieve participate Union in the party win-win, the characteristics of interdependent, core specialization and emphasizing the cooperation. The corporate trust each other, sharing the total risk and income, incomplete adopt behavior to maximize their own interests, not entirely take the common interests of maximizing behavior. Union is dynamic, and as long as the end of the contract, the two sides become single individual and in pursuit of self-interest maximization.

Logistics Integration. Integration of logistics is the logistics system as the core, by the producers, through logistics, marketing companies, until the consumer supply chain as a whole and systematic. The Logistics Integration is the new logistics model developed on the basis of the third-party logistics. In this mode, the logistics enterprise manufacturing enterprises to establish a wide range of agent or buyout relationship to form a more stable contractual relations and marketing enterprises, manufacturers of goods or information unified combination of processing orders require delivery by department to the shop. This mode also showed extensive exchanges supply information between users, and thus plays a surplus and deficiency, rational use of shared resources.

In the era of e-commerce, it is a more complete sense of the logistics distribution mode, advanced form and mature stages of the development of the logistics industry. The essence of logistics integration is a problem of logistics management, specialized logistics management and technical personnel, and makes full use of the specialized logistics equipment, facilities, to play specialized logistics operations management experience, in order to obtain the overall optimal effect.

\section{E-commerce LogisticsSystem Informational Major Problems inChina}

Low logistics quality. -commerce logistics accuracy in china is low, with the developed countries, there is a big gap. Mainly because of the distribution network intensive is not enough. E-commerce enterprise information network terminal in china is mainly used by large-scale enterprise units, far from widespread use. And the security of e-commerce distribution in china is low, cargo damage rate is high, also not timely delivery. Reasons, including improper packaging, backward logistics facilities, logistics and distribution management flawed various distribution sectors out of touch, not to mention the "seamless connection", and not enough awareness of our e-commerce business, customer service and distribution businesses.

High logistics distribution costs. The advantage of e-commerce with respect to traditional retail is price. E-commerce businesses must implement economic distribution. The one hand, to the extent possible to reduce distribution costs; the other hand, to make the distribution value-added occurred. Economic distribution needs professional logistics management talents to design specialized programs for businesses and consumers.

E-commerce in china does not yet have such conditions. The reason why cannot implement economic distribution is that our e-commerce logistics companies, business enterprises and distribution companies, which is mutual separation and compete with each other, the interests of the business cooperation between them is less than the competition. It cannot achieve any goods from the distribution of the starting point to the distribution end of resource integration and process optimization, also cannot effectively reduce distribution costs and improve distribution efficiency.

Logistics convenience. E-commerce logistics in china existence pick difficult, queries difficult, return difficult problem. E-commerce enterprises in china have not really establish a cargo tracking system, a library can only be found after the goods have been issued "on way "and unknowing the rest of the information. In the United States, UPS issued every single shipment by the network to allow customers to know the exact information and large distribution companies all should have this function. And returned difficult is a common problem of the majority of e-commerce in China. Consumers complain about it, and it also affected business and e-commerce businesses image. 
Serious waste of resources. A major characteristic of e-commerce B2C, C2C in china is the "scattered". B2C commodities and consumer dispersed, but a $\mathrm{C} 2 \mathrm{C}$ business is also decentralized. There is a huge waste of resources in the packaging and transport of goods, deviates from the advantages of low cost of manpower and e-commerce.

\section{The Development Trend of E-commerce Logistics System Informationization}

E-commerce systems, logistics and distribution systems, warehouse management systems, logistics parks, information technology and other systems is to mature slowly, through the development and operation of large-scale B2B e-commerce information platform, the integration of information technology, providing the perfect commodity display and electronic trading capabilities; through integrated logistics and distribution systems, warehouse management systems, transaction settlement system, the standard certification system. Provide comprehensive logistics services, warehouse management services, trading and settlement services, certification services, financial and information services, the establishment of large-scale comprehensive logistics and procurement of integrated information platform, yet to be developed.

Therefore, the development trend of e-commerce logistics system informational in china is the integration of Logistics and Purchasing. From the level of the specific technical, logistics and procurement of integrated information platform focus on considering the development in the following three aspects:

Play a logistics information collection function. Establish a large centralized data warehouse, make full use of network storage technology to achieve the logistics information safe and reliable mass storage and fast retrieval, and enhanced data disaster recovery capabilities. Vigorously promote the use of bar code, laser, scanning sensor, inventory, non-contact IC card technology and equipment to automate the data collection process, to improve the accuracy of the raw data collected.

Play the function of logistics information exchange. Promote the use of XMI. Especially ebXML as the representative of the exchange of information technology, make logistics information in the smooth exchange between the various types of heterogeneous systems, prepared the ability to exchange information with international interoperability.

Play a logistics information processing function. Through the analysis of collected and processed information, we can find and grasp the trend of the development of the logistics industry, law and problems. Timely provide intelligent information support to the Government and logistics companies.

\section{Acknowledgment}

The authors gratefully acknowledge the financial support from 2015 Transportation Vocational Education and Research Projects of National Transportation Vocational Education Teaching Guidance Committee under Grant No. 2015B44

\section{References}

[1] Su Xiaowen, The characteristics of the logistics management in the e-commerce environment, problems and countermeasures, in Commercial Era, 2010 (3).

[2] Luo Xuan, Status and development trend of China's e-commerce logistics system, in Economic Research Guide, 2010 (31).

[3] LIU Xiao-fen, Analysis of the current situation of China's e-commerce logistics, optional modes and development, in Scientific andTechnological Progress and Countermeasures, 2003 (9).

[4] Zhang Fang, China's e-commerce logistics mode selection, a master's degree thesis, 2007.

[5] Nan ShouXiang, Analysis of China's e-commerce logistics bottlenecks, in Modern Commercial, $2011(9)$. 